University of Nebraska - Lincoln

DigitalCommons@University of Nebraska - Lincoln

Congreso internacional sobre iconografía

precolombina, Barcelona 2019. Actas.

8-20-2020

\title{
Pars pro toto: "la parte por el todo". Una aproximación al estudio del significado en la iconografía del Perú precolombino
}

Marisa Sánchez David

Follow this and additional works at: https://digitalcommons.unl.edu/actas2019

Part of the American Material Culture Commons, Indigenous Studies Commons, Museum Studies Commons, Other History of Art, Architecture, and Archaeology Commons, and the Other Languages, Societies, and Cultures Commons

This Article is brought to you for free and open access by the Zea E-Books at DigitalCommons@University of Nebraska - Lincoln. It has been accepted for inclusion in Congreso internacional sobre iconografía precolombina, Barcelona 2019. Actas. by an authorized administrator of DigitalCommons@University of Nebraska - Lincoln. 


\title{
Pars pro toto: "la parte por el todo". Una aproximación al estudio del significado en la iconografía del Perú precolombino
}

\author{
Marisa Sánchez David
}

Investigadora independiente, vinculada al Grup d'Estudis Precolombins, Universitat Autònoma de Barcelona

\section{Introducción}

La comprensión de la imagen en las antiguas sociedades precolombinas nos acerca a comprender las mentalidades de los pueblos del pasado. Nos ilustran sobre cómo se vivieron los cambios y la evolución en estas sociedades y que trascendencia tuvieron para los miembros de cada comunidad.

Partiendo de la tipología de objetos encontrados en las sociedades precolombinas, y acotando este hecho a algunas culturas de la geografía peruana, podemos observar la ofrenda de cerámicas en forma de alguna parte concreta del cuerpo (como en el caso de las culturas Moche, Wari, entre otras). La representación de un brazo, un pie, una cabeza, una pequeña estatuilla e incluso algún órgano interno se han encontrado en lugares sagrados o en las tumbas. La cuestión planteada es: ¿se trata de una ofrenda?; ¿podemos hablar de sacrificio?. ¿O tal vez simboliza "la parte por el todo" (pars pro tuto) dentro de un sistema de creencias para estas sociedades?.

\section{Metodología}

El estudio de la iconografía en sociedades ágrafas nos permite una aproximación a su pensamiento ideológico, político, económico y religioso. Para comprender mejor su funcionamiento se hace necesario encontrar un método que nos permita proponer nuevos modelos de razonamiento para repensar la imagen desde su propio

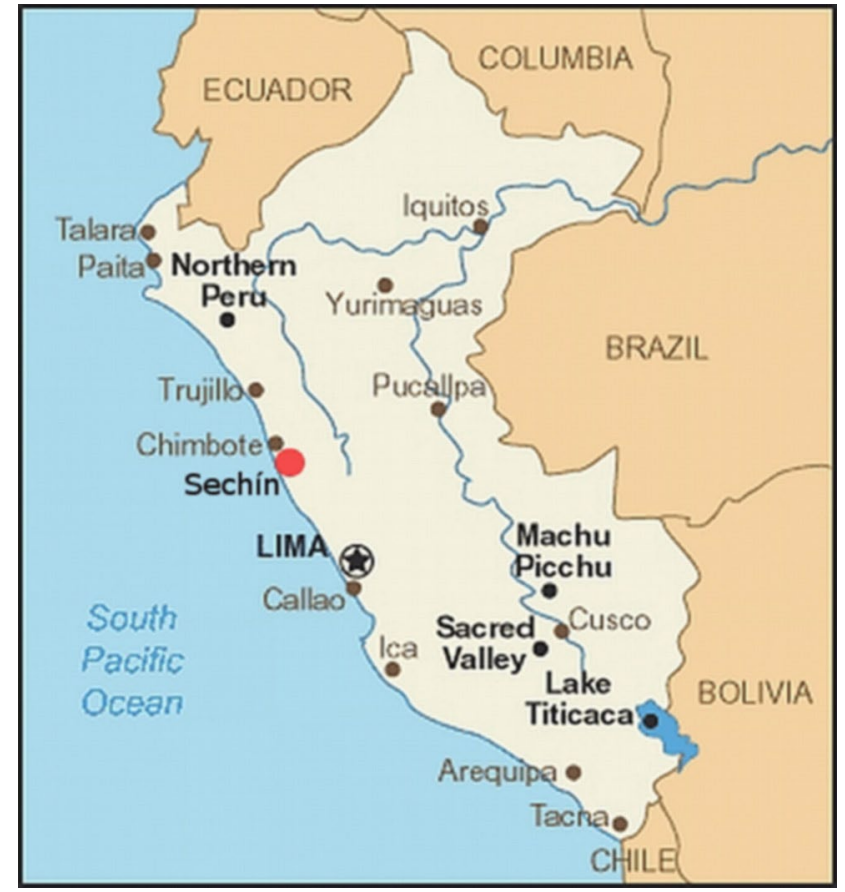

Foto 1. Mapa. Fotografía correspondiente al artículo de Lizardo Tavera Vega. http://www.arqueologiadelperu.com. ar/cerrosechin.htm

lenguaje; un método de análisis que trate las imágenes en estas sociedades como unidades dentro de un sistema global, teniendo en cuenta el gran número de condicionantes que existen y su vinculación con el contexto en que se desarrollan. 


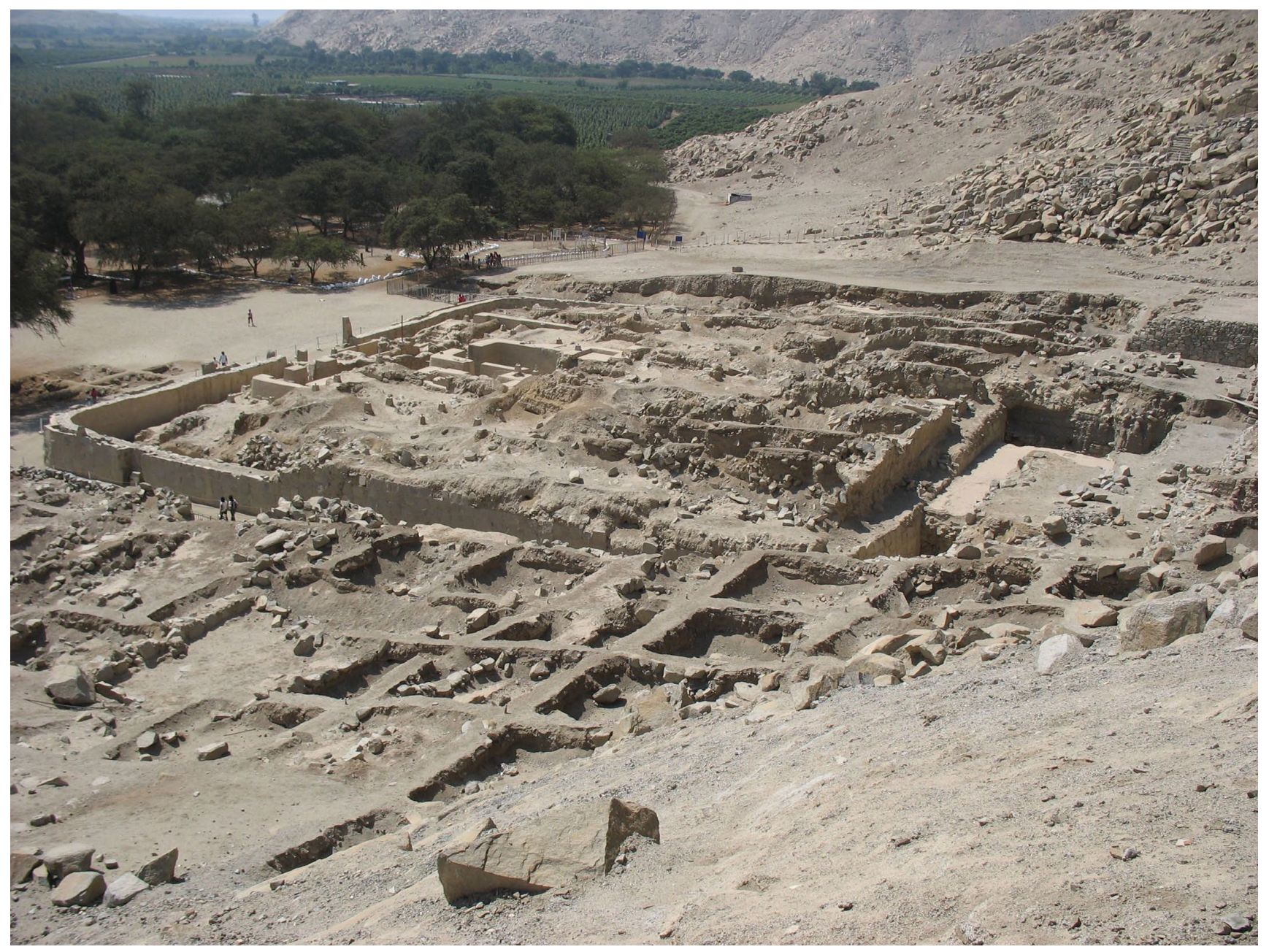

Foto 2. Vista del conjunto arqueológico de Cerro Sechín.

En este trabajo se intenta realizar una nueva lectura iconográfica de las imágenes plasmadas en la fachada del Templo Lítico de Cerro Sechín.

\section{La ofrenda o "exvoto"}

Desde tiempos pasados los pueblos han manifestado su ideología a través de ceremonias y prácticas rituales de acuerdo al contexto en que se ha desarrollado su cultura. En muchos actos rituales de la antigüedad y todavía en nuestros días, los objetos que forman parte de los mismos se denominan exvotos.

Una ofrenda o exvoto es una expresión de religiosidad de carácter popular con arraigadas raíces en el comportamiento humano. Al mismo tiempo representa una forma de relación con lo sobrenatural, repleta de una fuerte carga histórica y etnográfica. Consta de una fuente de información plena de simbolismo en la búsqueda conceptual de un sistema de creencias. Es decir, una determinada manera de ver, sentir y repensar el mundo.

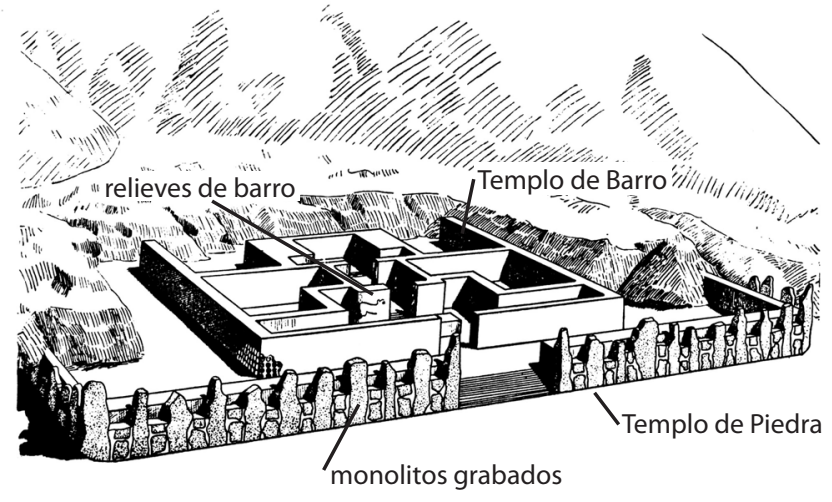

Foto 3. Dibujo. Templo de Sechín. Reconstrucción publicada en el libro de Julio C. Tello Arqueología del Valle de Casma (1937). 


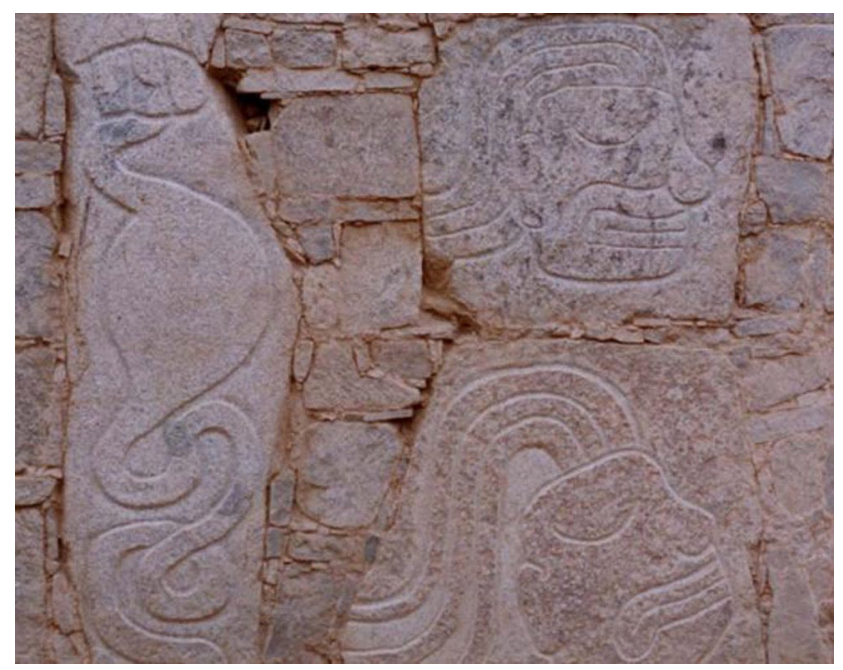

Foto 4. Detalle cuerpos seccionados.

El exvoto u ofrenda da a conocer el favor que se ha recibido. Pero también puede representar aquello que se anhela, como si se tratase de un acto que se "da" para de este modo poder ser retribuido. Para que se lleve a buen término este proceso, el acto debe ir acompañado de acciones, de imágenes que divulguen la acción llevada a cabo por un ser sobrenatural. Esta acción normalmente tiene un carácter benefactor, aunque también puede querer representar conseguir todo lo contrario. En este sentido, un exvoto u ofrenda es un medio con el que se evidencia la acción; una suerte de plegaria o ruego magnificado por la presencia del objeto materializado.

La asociación entre el oferente y el dios está vinculada al cumplimiento del favor solicitado. Los motivos pueden ser muy diversos: una curación, el anhelo de la victoria en una batalla, calmar la tempestad frente a las cosechas, aplacar la fuerza del fenómeno climatológica ENSO (El Niño), entre otros. Pero todos ellos presentan un objetivo común: tener el convencimiento de que los poderes sobrenaturales estarán a su favor. La ofrenda es, en consecuencia, una expresión simbólica de querer alcanzar ese favor de los dioses, o bien dar las gracias por el favor otorgado y refleja un deseo de perduración en el tiempo mediante la durabilidad del material empleado.

\section{Ubicación}

Cerro Sechín está ubicado en la provincia de Casma, departamento de Ancash, Perú, a 90 metros sobre el nivel del mar, cerca de la confluencia de los ríos Casma y Sechín. El complejo tiene una cronología que abarca del 2.400 al 1.500 a.C.

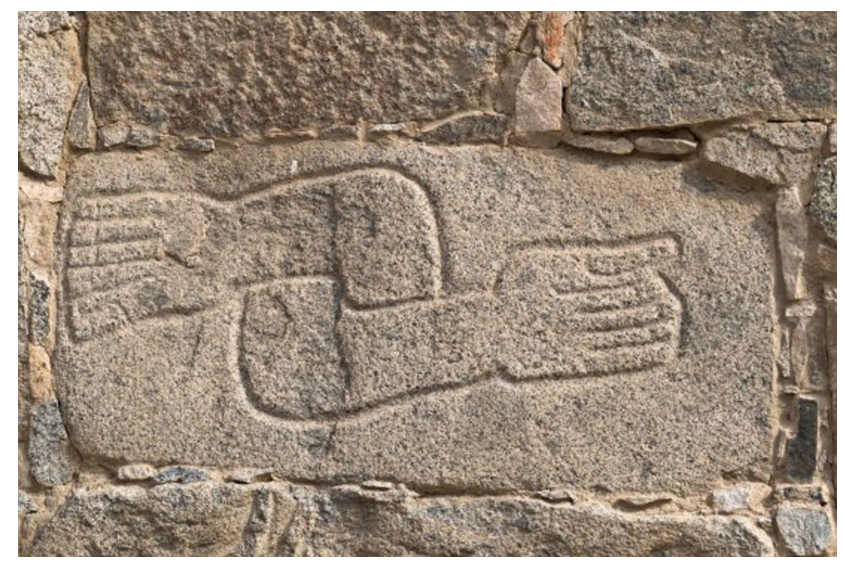

Foto 5. Detalle brazos.

La ubicación del templo aparece en un área que permite un dominio visual amplio desde dos puntos de vista distintos: desde la propia estructura del templo hacia el área circundante, y desde su alrededor, hacia el templo mismo.

La cantera de donde se extrajo el material fue el cerro Sechín, contiguo al monumento, en el valle de Casma.

\section{Historia de las investigaciones}

El primer investigador en trabajar el sitio fue el peruano Julio César Tello en 1937. Después de Tello otros investigadores trabajan la cuenca de Casma: Frédéric Engel, Edwuard Lanning, Donald Collier, Donald Thompson, Rosa Fung, La Expedición Japonesa, Terence Grieder, H. Bischoff, entre otros.

\section{Iconografía}

Los motivos representados, realizados en granodiorita, han sido clasificados según varios autores (Kroeber, Tello, Bueno, Samaniego, Jiménez Borja) en dos grandes bloques: guerreros y cuerpos mutilados o despojos humanos.

Estas imágenes tienen normalmente un significado trascendente, ya sea religioso o social, como expresión de poder y medio con el que se transmiten mensajes desde los grupos dominantes a los dominados o al resto de la comunidad en las que se integran. Los grandes bloques con iconografía incisa transmiten en el espectador una visión de durabilidad, fuerza, poder y temor al mismo tiempo. 


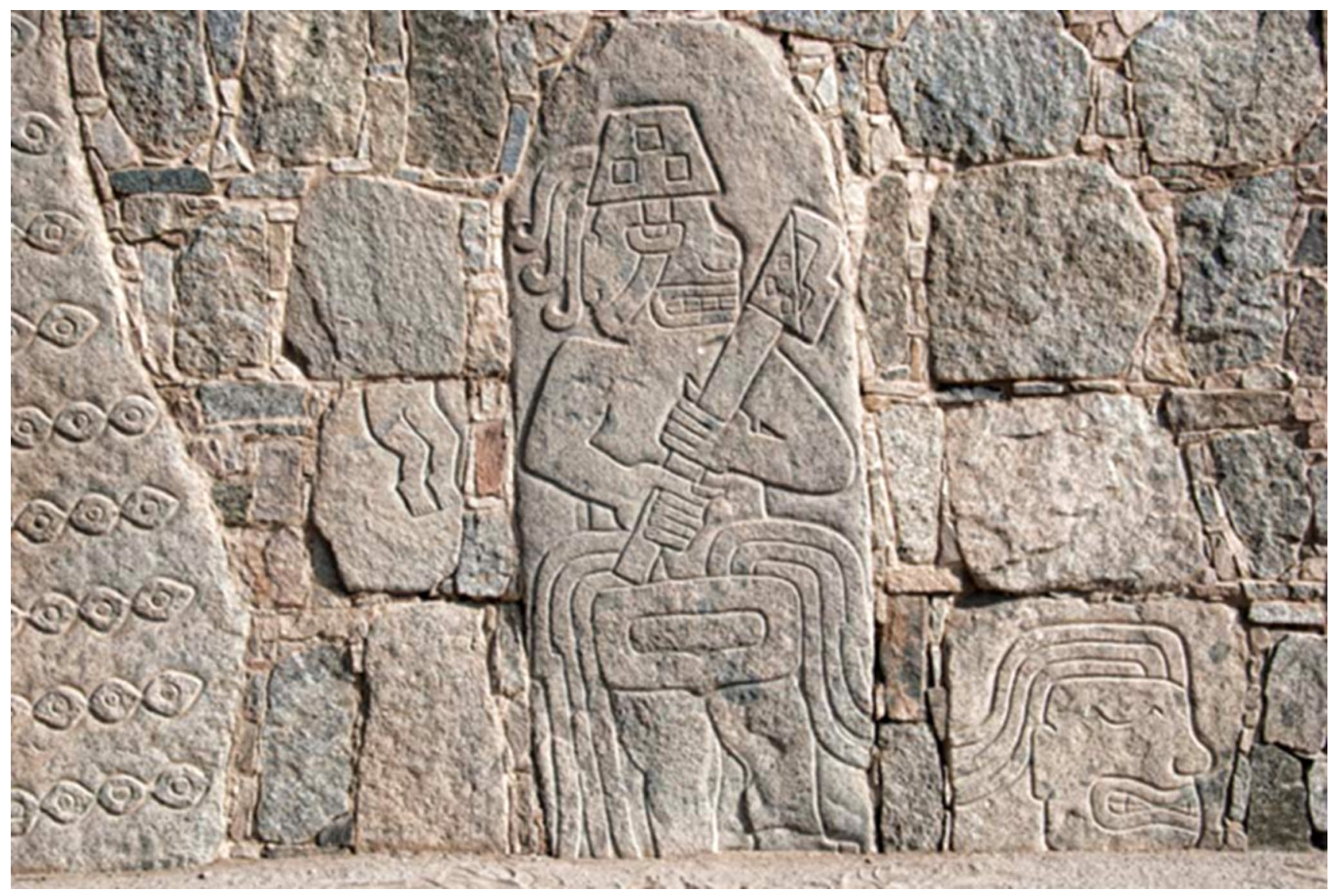

Foto 6. Sacerdote o dignataria ostentanto un cetro o bastón ceremonial.

Los guerreros están representados con la cabeza, brazos y piernas de perfil. El tronco y la pelvis se muestran de frente. Visten un taparrabo, un gorro trapezoidal, pintura facial y sostienen un arma o cetro con las manos. La uña del dedo pulgar es especialmente larga y afilada. La boca muestra los dientes apretados y los ojos con midriasis (dilatación de las pupilas), consecuencia de la ingesta de algún producto con propiedades psicotrópicas. El gesto con la pierna adelantada sugiere sensación de movimiento.

El siguiente grupo está integrado por cabezas, ojos, orejas, brazos, piernas, vísceras, huesos y cuerpos seccionados.

\section{Teorías sobre la función de este templo}

Siguiendo las investigaciones realizadas por diferentes autores, podemos afirmar que la iconografía de la fachada del Templo Lítico de Cerro Sechín podría haber tenido diferentes funciones, algunas de las cuales ya son conocidas en la bibliografía: a) Un templo donde se ofrecerían sacrificios a los dioses;

b) Una escuela de anatomía donde estudiar el comportamiento anatómico y fisiológico del ser humano;

c) Una especie de "Palacio de Justicia" donde los castigos no quedarían impunes;

En el presente artículo se expresa la idea de que dichas imágenes también podrían aludir a:

d) Exvotos u ofrendas. Se dedicarían ofrendas por una gracia recibida o bien por la concesión de un deseo futuro;

e) Sentido apotropaico. Efecto apotropaico es el mecanismo de defensa que la superstición o las pseudociencias atribuyen a determinados actos, rituales, objetos o frases formularias, consistente en alejar el mal o protegerse de él o de los malos espíritus, o bien de una acción mágica maligna. 
Un ejemplo de sentido apotropaico sería la representación de la cabeza de Medusa, de origen etrusco, y más tarde representada en el pecho de las corazas de los soldados romanos como producto de la continuidad cultural, las cuales ejercían una acción protectora sobre los mismos. A su vez los romanos cortaban las manos a los suicidas como acto apotropaico para defenderse del mal espíritu.

Las imágenes concebidas en los frisos del Templo Lítico de Cerro Sechín nos hablan de muerte: cuerpos mutilados, miembros seccionados, cabezas decapitadas,... como si mostraran la fragilidad del cuerpo humano ante la adversidad y el ocaso de la vida (muerte). Pero, ¿no será todo lo contrario?.

En muchas sociedades antiguas el ritual de las cabezas cortadas estaba asociado a la creencia de que el alma del difunto se localizaba en el interior del cráneo. Este conservaba parte de la energía del difunto, la cual pasaría a aquel que la conservara. De este modo el ritual de la decapitación no solo permitía cuantificar las bajas de los contrarios y evidenciar la victoria como símbolo de poder, sino también era una manera de apropiarse de la fuerza de los oponentes vencidos. Las cabezas eran separadas del cuerpo de las víctimas y han sido tratadas como instrumentos mediáticos para el observador.

\section{Tipología de lenguaje o código empleado.}

Cuando observamos la iconografía de la fachada del Templo Lítico observamos un lenguaje visual, simbólico y abstracto que provoca una relación con el espectador de modo que éste participe activamente interpretando el lenguaje empleado, pensando la imagen y dotándola de sentido.

Con la finalidad de hacer una lectura de estas imágenes se emplea en el presente trabajo un método iconográfico basado en los tres elementos más importantes de la semiótica, los cuales permiten establecer una relación entre el signo y la cosa o referente. Son el icono, el índice y el símbolo.

a) Icono. El icono se construye a partir de una relación directa con la realidad, al tiempo que la representa, transforma y reconstruye en un proceso semiótico (Zunzunegui, 1985). Es análogo al objeto que se sustituye.

b) Índice. Funciona como signo de acuerdo con una relación causal existente entre dos fenómenos de carácter temporal-local, Por ejemplo, el humo es un índice de fuego (Peirce, 1934). Funciona como signo de acuerdo a una relación causal.

c) Símbolo. Para Peirce (1934) y Morris (1936), el símbolo es un signo que representa un objeto por

\begin{tabular}{|l|l|}
\hline \multicolumn{1}{|c|}{ Lenguaje } & \multicolumn{1}{|c|}{ Relación con el espectador } \\
\hline Lenguaje visual, simbólico y abstracto & $\begin{array}{l}\text { Espectador participa activamente, pensando la } \\
\text { imagen y dotándola de sentido }\end{array}$ \\
\hline
\end{tabular}

Tabla 1. Tipología de lenguaje o código empleado.

\begin{tabular}{|l|l|l|}
\multicolumn{2}{c}{ Icono } & \multicolumn{2}{c|}{ Símbolo } \\
\hline Fuego & Humo & Llama \\
\hline Agua & Planta (Cosecha) & Pan \\
\hline Brazo & Parte del cuerpo humano. & $\begin{array}{l}\text { Muerte / Sacrificio / Castigo- } \\
\text { Justicia / Escuela de anatomía / } \\
\text { Pierna }\end{array}$ \\
Órgano interno & & $\begin{array}{l}\text { Exvoto-Ofrenda / Elemento para } \\
\text { alejar el mal (sentido apotropaico). }\end{array}$ \\
\hline
\end{tabular}

Tabla 2. Icono, Índice y Símbolo. 


\begin{tabular}{|c|c|c|c|c|}
\hline $\begin{array}{l}\text { Unidad } \\
\text { Simbólica/ } \\
\text { Motivo }\end{array}$ & \multicolumn{2}{|c|}{ Estratos/ Genealogía Simbólica } & $\begin{array}{c}\text { Efecto/ } \\
\text { Alusión Directa }\end{array}$ \\
\hline Forma & Primario & Secundario & Terciario & Contenido \\
\hline & $\begin{array}{c}\text { Referencia } \\
\text { Original. } \\
\text { ¿Por qué se } \\
\text { representan } \\
\text { este tipo de } \\
\text { imágenes?. }\end{array}$ & $\begin{array}{c}\text { Propaganda } \\
\text { subliminal } \\
\text { indirecta. } \\
\text { Crear } \\
\text { sentimiento de } \\
\text { temor. }\end{array}$ & $\begin{array}{c}\text { Propaganda } \\
\text { política directa. } \\
\text { Transmisión de } \\
\text { la idea de poder. }\end{array}$ & \\
\hline
\end{tabular}

Tabla 3. Genealogía simbólica 1.

convención y que funciona basado en una relación al azar entre el sígnico y el concepto. Es decir; su comprensión exige una interpretación y solamente tendrá sentido dentro de la comunidad o el contexto dónde ha sido creado. Representa el objeto por convención.

Desde la Antigüedad, la representación de imágenes se ha utilizado a favor de los intereses políticos de un grupo dominante como propaganda del poder. Si analizamos la iconografía desde su genealogía simbólica basada en tres estratos o niveles (primario, secundario y terciario), observamos lo siguiente:

De todo ello se desprende que lo importante es conocer por qué y para qué se ha utilizado el símbolo, a qué intereses responde y a qué época y a qué mentalidad hace referencia.

El arte es propaganda del poder, recoge sus aspiraciones, sus dudas, sus intereses, pero al mismo tiempo puede reflejar los temores de un pueblo. La imagen se convierte en un instrumento eficaz para la transmisión de unos valores en una sociedad ágrafa.

El poder precisa que las obras plasmadas reflejen de forma evidente el dominio ejercido, pues la representación plástica actúa sobre el imaginario social y genera relaciones de hegemonía desde el inconsciente colectivo. Poder y representación artística van de la mano como un medio poderoso de expresión. La visualización de la sangre fluyendo de los cuerpos, la evisceración de los órganos mostrando el complejo sistema anatómico humano, muestran la comprensión de su funcionamiento, como un elemento de aproximación a la vida, donde estas escenas podrían tener la misión de repeler todo aquello que muestran sus frisos, como si se tratase de un sistema mágico "apotropaico", en donde la imagen repele o ahuyenta todo elemento negativo para la comunidad y evoca, como un talismán, mediante la fuerza contraria, la continuidad de la vida y la sociedad.

\begin{tabular}{|l|l|l|l|l|}
\hline $\begin{array}{l}\text { Unidad } \\
\text { Simbólica/ } \\
\text { Motivo }\end{array}$ & \multicolumn{2}{|l|}{ Estratos/Genealogía Simbólica } & $\begin{array}{l}\text { Efecto/ } \\
\text { Alusión Directa }\end{array}$ \\
\hline Forma & Primario & Secundario & Terciario & Contenido \\
\hline & $\begin{array}{l}\text { Referencia } \\
\text { Original. } \\
\text { Temor } \\
\text { Muerte } \\
\text { Devastación } \\
\text { Poder }\end{array}$ & $\begin{array}{l}\text { Propaganda } \\
\text { subliminal } \\
\text { indirecta. } \\
\text { Vida } \\
\text { Agua Cosechas } \\
\text { Paz }\end{array}$ & $\begin{array}{l}\text { Propaganda política } \\
\text { directa. } \\
\text { Estabilidad } \\
\text { Sedentarismo } \\
\text { Prosperidad }\end{array}$ & \\
& & Rad & \\
& &
\end{tabular}

Tabla 3. Genealogía simbólica 2. 


\section{Conclusión}

En las imágenes plasmadas en la fachada del Templo Lítico de Cerro Sechín existe un despliegue de cuerpos y vísceras seccionados decorando los grandes frisos externos del reciento, formando un gran muro que delimita el área sagrada. Estas representaciones están integradas por cabezas, ojos, orejas, brazos, piernas, vísceras, huesos y cuerpos seccionados.

Desde la Antigüedad, la representación de imágenes se ha utilizado a favor de los intereses políticos de un grupo dominante como propaganda del poder.

El arte es propaganda del poder, recoge sus aspiraciones, sus dudas, sus intereses, pero al mismo tiempo puede reflejar los temores de un pueblo. La imagen se convierte en un instrumento eficaz para la transmisión de unos valores en una sociedad ágrafa.

El poder precisa que las obras plasmadas reflejen de forma evidente el dominio ejercido, pues la representación plástica actúa sobre el imaginario social y genera relaciones de hegemonía desde el inconsciente colectivo. Poder y representación artística van de la mano como un medio poderoso de expresión.

En el momento en que se reconoce la pertenencia a un mismo grupo o a un culto común a los antepasados, este sentido compartido se convierte en un elemento útil en el ejercicio del control del territorio y en el acceso a determinados recursos para la comunidad. Al mismo tiempo, existe una voluntad política del grupo dominante de "controlar", a través de la adhesión de un culto colectivo, a toda una sociedad que lo integra y sigue.

En consecuencia, podemos decir que este complejo arquitectónico representa un instrumento político fundamental en una sociedad que no ha creado sus propias reglas de convivencia mediante un código escrito, de manera que opta por desarrollar formas simbólicas eficaces que ejecuten dicha función.

La iconografía de la fachada del Templo Lítico de Cerro Sechín nos hace pensar en una fase de cambio del ritual funerario en el que podrían realizarse sacrificios y ofrendas en el área exterior del templo. Es decir; el desarrollo de un ritual realizado en origen en un ámbito cerrado (el templo de adobe, de época anterior y anexo al de piedra), en donde sólo tendrían acceso un grupo limitado de personajes (el líder de la comunidad, personajes de alto estatus, sacerdotes), deriva con el tiempo a un espacio abierto, frente al templo, quizás en una gran plaza, en donde el número de espectadores como actores pasivos del ritual ha crecido considerablemente, de manera que el acto en sí mismo se convierte en un elemento manifiesto y por tanto, compartido. Se ha pasado de un culto mistérico, a un culto no mistérico, en dónde la iconografía refleja aquello que sucede en su exterior, ante una presencia comunitaria.

Este cambio de ritual implica a su vez un cambio social y político: una ritualidad en un momento reservada a un limitado número de personas, de alguna forma ahora es "democratizada" y compartida por un grupo más amplio de espectadores. Este hecho no implica solamente una evolución del culto, sino puede también representar la consecuencia de una organización política articulada y compleja que, mediante el acto repetitivo del ritual y la fragmentación del cuerpo de las personas sacrificadas, confirma y amplifica la adhesión al grupo.

La visualización de la sangre fluyendo de los cuerpos, la evisceración de los órganos mostrando el complejo sistema anatómico humano, muestran la comprensión de su funcionamiento, como un elemento de aproximación a la vida, dónde estas escenas podrían tener la misión de repeler todo aquello que muestran sus frisos, como si se tratase de un sistema mágico "apotropaico", en donde la imagen repele o ahuyenta todo elemento negativo para la comunidad y evoca, como un talismán, mediante la fuerza contraria, la continuidad de la vida y la sociedad.

La violencia aparece a menudo asociada al poder como forma de sustentación o expansión de este. Sirve para imponer, de manera individual o colectiva, la voluntad arbitraria o subjetiva de unos sobre otros. La escenificación de la violencia a través de la exposición pública desprende una fuerte carga simbólica que está claramente presente en nuestro imaginario colectivo desde tiempos pasados. Estas imágenes tienen normalmente un significado trascendente, ya sea religioso o social, como expresión de poder y medio con el que se transmiten mensajes desde los grupos dominantes a los dominados o al resto de la comunidad en las que se integran. Los grandes bloques con iconografía incisa transmiten en el espectador una visión de durabilidad, fuerza, poder y temor al mismo tiempo.

Las imágenes del Templo de Lítico de Cerro Sechín muestran la estrecha relación entre las élites y la costumbre de seccionar el cuerpo humano y decapitar a los enemigos como prueba de valor y prestigio. Este acto servía de nexo de cohesión con la comunidad, dotando al espectador de un sentido de identidad y pertenencia 
al grupo vencedor. Al mismo tiempo, reforzaba la imagen de los líderes y su legitimación para ejercer el control sobre el resto de la comunidad. Pero podría también ejercer la función de alejar aquello representado. En este sentido podemos decir que estas imágenes pueden tener el poder de repeler el mal, siendo un intento de oponerse a todo cuanto representa la muerte con todo lo que representa la vida. La iconografía tendría entonces como función alejar a la muerte para que haya vida, ejerciendo un sentido contrario a aquello que nos brinda la imagen.

En su iconografía existe un despliegue de cuerpos y vísceras seccionados decorando los grandes frisos externos del reciento, formando un gran muro que delimita el área sagrada. En ese sentido el mensaje simbólico de su iconografía alude a una ocupación política de su territorio, legitimado como un lugar "intocable" a la vez que sagrado. El lugar tuvo que ejercer como un gran elemento de cohesión dentro de un grupo social mediante la ejecución de rituales colectivos en donde el objetivo principal de los mismos sería el desarrollo de pertenencia común a un grupo, es decir, la búsqueda de un sentido de identidad.

\section{Bibliografía}

MARTIN GONZÁLEZ, J.J., 1989: “Iconografía e iconología sobre métodos de la Historia del Arte". Cuadernos de arte e iconografía, Tomo 2, Número 3, pp: 11-26.

MORRIS, Ch. 1936: Fundamentos de la teoría de signos. Paidós, Barcelona.

PEIRCE, Ch. 1934: "Pragmatism and pragmaticism". Collected Papers of Charles Sanders Peirce. Harvard University Press. Cambridge.

RODRÍGUEZ BECERRA, 1989: "Formas de la Religiosidad Popular: El exvoto": su valor histórico y etnográfico". La Religiosidad Popular, I: 123-134. Ed. Anthropos /Fundación Machado.

SALCEDO GARCÉS, 1995: "La Hispania bárbara y la Hispania civilizada: la imagen de un concepto". Studia historica. Historia antigua, no 13-14, pp. 181-194.

SALCEDO GARCÉS, 1999: "Imagen y persuasión en la iconografía romana”. Iberia: Revista de la Antigüedad, 2 pp. 87-110.

SAMANIEGO, L., 1972: Sechín. Pasado, Presente y Futuro. Chimbote, 12: 37-44. Chimbote, Perú.

SAMANIEGO, L., 1973: Los Nuevos Trabajos Arqueológicos en Sechín, Casma, Trujillo, Perú.

ZANKER, P., 1992: Augusto y el poder de las imágenes. Madrid. ZUNZUNEGUI, S., 1984: Mirar la Imagen. Universidad País Vasco, San Sebastián. 